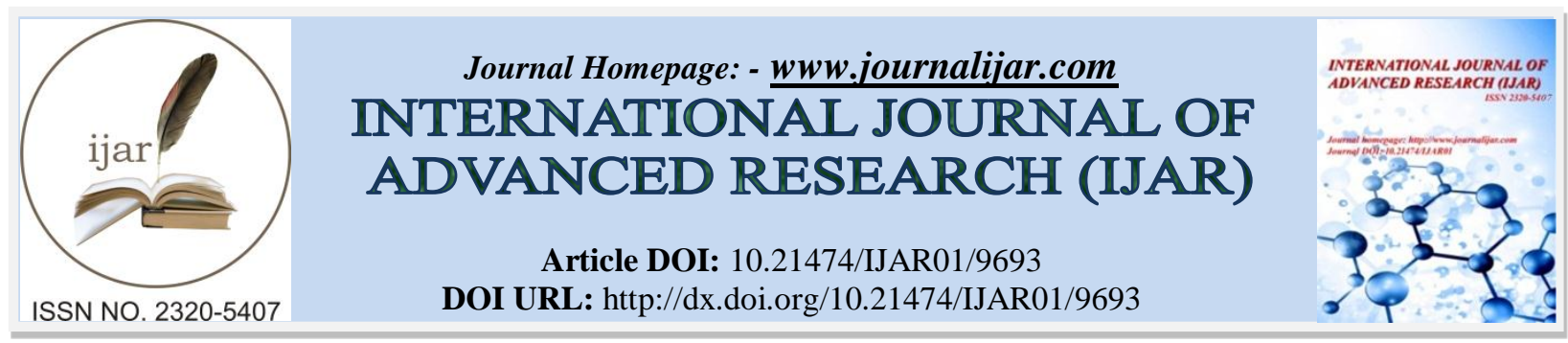

RESEARCH ARTICLE

\title{
PROMOTING TOURISM IN NIGERIA THROUGH AN ENHANCED TOURISM MANAGEMENT SYSTEM - A PRELIMINARY STUDY.
}

Wada S. M. ${ }^{1}$, Offiong N. M. ${ }^{1}$ and Chaku S. E. ${ }^{2}$.

1. Department of Computer Science, Nasarawa State University, Keffi, Nasarawa.

2. Department of Statistics, Nasarawa State University, Keffi, Nasarawa State, Nigeria.

\section{Manuscript Info}

Manuscript History

Received: 08 July 2019

Final Accepted: 10 August 2019

Published: September 2019

Key words:-

Tourism, Management Information

System, developing countries.

\begin{abstract}
In an era where information plays a vital role in our society because its use is unavoidable in our day-to-day activities; tourism has become popular as a leisure way of travel and it relies on information technology in order to deliver quality products and services to its customers. This paper proposes an Automated Tourism Management System (ATMS) to curb the peculiar problem of the current manual systems used by tourist centres. The slow, poor, tedious, inadequate, stressful and error-prone manual system currently used for tourist activities in Nigerian tourism sector is making the tourist management business difficult. This research work combines the concept of web based application and takes advantage of information and communication technology to provide all the necessary information needed by a tourist to embark on a tour. This research work also analyses the problems associated with the current manual system and provides a solution by designing and implementing a web based ATMS using the V-Shaped model of the SDLC and the system was implemented using PHP and MYSQL. The result obtained shows a user friendly system that is easy to use by both the administrators and tourists.
\end{abstract}

Copy Right, IJAR, 2019,. All rights reserved.

\section{Introduction:-}

Over the years, fun seekers around the world are on the lookout for places they could visit and have fun in Nigeria. But due the lack of automated systems that are readily available and holds a database of likely places, they tend to travel abroad to have fun elsewhere. This portend a very serious problem for the Nigerian tourism sector. This paper presents a careful work done on the area of tourism with the design and implementation of an Automated Tourism Management System (ATMS) that serves as a database and a reference point for fun seekers and holiday makers. This system is particularly of interest because there are no national tourism management systems in Nigeria at the moment that has all the information a tourist need for the over 7000 tourists destinations in Nigeria (Mulkat and Mukail, 2015)

The 21st century is an era of information economy because information plays a vital role in all aspects of our lives. With economic development, leisure time continues to increase and therefore tourism has become popular and is regarded as one of the fastest growing industries in the world. In this industry, it is vital that information needs of potential customers are satisfied quickly. In the past, tourist centres rely on manual systems or analogue media but

Corresponding Author:-Wada S. M..

Address:-Department of Computer Science, Nasarawa State University, Keffi, Nasarawa. 
over the years, as a result of information becoming an integral part of the society, tourist centres began using the internet especially for online booking services. Only a small fraction of tourist centres fully utilizes the internet to showcase their assets and services. Tourism provides a lot of benefits and the most prominent is its economic impact which represents a significant portion of income for many countries across the globe thus serving as a sustainable development in its economy. Tourism in Nigeria faces numerous problems due to the manual system used by tourist centers in the country, so there is need for tourist centers to find a new way to showcase their assets and services and a Tourism Management System provides the perfect platform where information needs of tourists are satisfied.

\section{Literature Review}

Tourism has become one of the world's major economic success that has embraces nearly all aspects of our society. It is widely acknowledged as one of the fastest growing industry globally (Newsome et al., 2002; Basu, 2003). Tourism Management System is a web based system because it is clear that the web, unconstrained by geographical boundaries is more efficient vehicle and paves way to work on truly global scale. In science and technology, the desire for improvement is a constant subject which triggers advancements. This is visible in every development and the tourism board is not an exemption. The use of information technology in our day to day activities is now unavoidable (Agianaku, 2012). The development of information technology has a high influence on tourism development. Poor information results to inadequate analysis, which leads to misguided policies on Tourism Management. In Tourism developments, destination information and Management Systems are used to guide tourists and provide information to both tourists and management of the tour sites.

\section{Manual Tourism System}

In analysing the existing manual system, it was discovered that tourists do not have adequate means to obtain vital information needed for their impending travel and tour. Tourists have to make contact with the tourist centres via phone or fax in order to obtain relevant information and in most cases, response is slow. Ways of finding facts about tourism activities as regard to fees, registration, payment, hotels and other information is to visit the centres itself which is stressful and time consuming to both tourist and management of the tour site. Records are stored as filebased system which is inadequate because records could get missing or damaged. The manual system used is prone to errors, inconsistent, lengthy and tedious to both the tourist and management of the tour sites.

\section{Tourism Management System}

A Tourism Management System is a web based application that provides information on tour sites and hotel availability, enable online registrations and payments and also tour bookings. The proposed system showcases list of tour areas in a state along with information pertaining each. List of hotels near the tourist attractions is showcased to enable far distant tourists make reservations for accommodations prior to visit. A tourist register via a registration form in which the tourist record is automatically stored in a database and the tourist print a receipt upon completing the registration. The tourist gets to log in into his account to make tour booking where he gets to choose the tourist attraction state, tour area and tour guide. The tourist can proceed to make payment via the system. The receipt is taken to the management staff from where the tour guide is assigned to the tourist for easy identification and movement to area that the tourist has chosen and then, tour begins. The system has a nice user friendly interface that gives tourists fast and easy of access to information. This work suggests ways in which clear information can be provided to both tourists and the management as a whole.

\section{Benefits of Tourism \\ Economic:}

The major benefits of tourism in a region or a country is its economic benefits. Tourism can also benefit economies at regional and local levels, as money comes into urban and rural areas which in turn stimulate new business enterprise and promotes a more positive image in an area (Cooper et al., 1993). Some of the economic benefits of tourism are:

\section{Creation of Jobs or Employment:}

Another major direct economic effect of tourism relates to employment (Inskeep, 1991). Tourism is a highly labour intensive industry which provides employment several times more than normal manufacturing industries. It depends very much on a large number of people with various levels of skills and abilities (e.g. waiters, tour guides, hotel managers, etc.). 


\section{Increase in Standard of Living:}

Due to the rule played by tourism in the growth of the economy of a nation, it increases the standard of living of people by offering numerous new and improved jobs which in turn improves the quality of people's life.

\section{Generation of National Income:}

Tourists have to pay for different goods and services in the host country, so tourism constitute a demand for goods and services. In a labour-intensive industry such as tourism, a large part of income comes from wages and salaries earned by people who are directly or indirectly involved in the industry.

\section{Cultural:}

Tourism promotes cultural exchange as tourists travel from one place to another. Upon their travel, tourists encounter new customs and traditions and they also travel along with their own customs, so as a result of this, there is exchange in culture between the tourists and the inhabitant of their place of visit. It also makes people have tolerance, respect and appreciate each other's culture.

\section{Environmental:}

We are surrounded with a lot of beautiful natural resources in our ecosystem, so there is a need to conserve these resources. Tourism provides numerous financial support for the preservation of our natural resources such as setting up wildlife and forest reserves and also conservation of archeological treasure and ancient monuments which in turn provides an enchanting picture that attracts tourists.

\section{How a tourism management system works?}

A Tourism Management system is a system that provides clear and effective information to both tourists and management of the tour sites (TMS) which contains three cardinal parts:

\section{Administrator:}

The administrator is the backbone of the system that manages; tour areas, state settings, payment, hotels, registrations, booking, tourists and tour guides.

\section{Server:}

The server receives and processes requests from both administrator and tourists. It sends back the appropriate information that is requested.

\section{Tourist:}

The tourist is a subsystem of the Tourism management system that views tourist attractions and hotels, book tour, and also make registration payments.

\section{Methodology: -}

The methodology that was adopted for this study is the V-shaped model of the Software Development Life Cycle (SDLC). V-shaped model which is also known as the Verification and Validation model is based on a phase where testing is carried out in each of the corresponding development of the system. This is directly connected to the testing phase for each activity that are associated with development. Lastly, the model has a test phase which executes in a sequential manner. It is chosen because the research work is small where requirements are well understood. The phase in the model are:

\section{Requirements:}

feasibility study is carried out to obtain vital data and information relevant for this study. The various ways data are collected include; Primary and secondary source. The functional requirements of the system are: Administrator, Tourist and database modules.

\section{High level design:}

This explains the architecture of the system where it shows the relationship between modules and functions of the system. Unified Modelling Tools (UML) Activity and Use Case diagrams were used to model this phase. 


\section{Design Phase:}

Requirement Analysis:

At this phase, we liaise with tourism service providers and users by obtaining relevant information through questions and questionnaires. This enabled us to gather all the information needed to proceed with the model architecture.

\section{System Design:}

A holistic design of the system was carried out based on the requirements gathered. The system engineering was carefully planned and designed.

\section{Architectural Design:}

At this stage, we broke down the system design into modules and assigned different functionalities to these modules. The relation between the different classes (e.g. tourist and the system administrator) are clearly presented in a way that is could be understood.

\section{Module Design:}

All the phases of our system are presented in understandable modules to show the workflow of the system and for easy implementation.

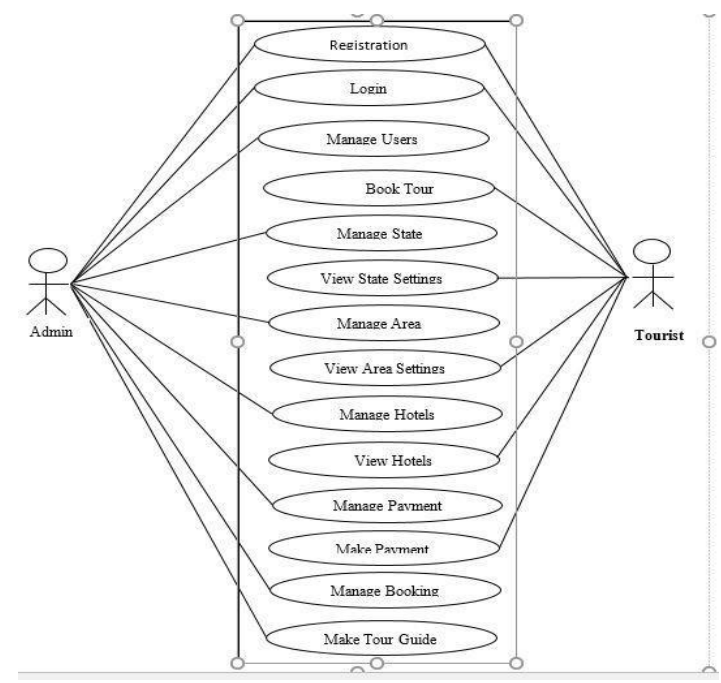

Fig 1:-UML Diagram for administrator

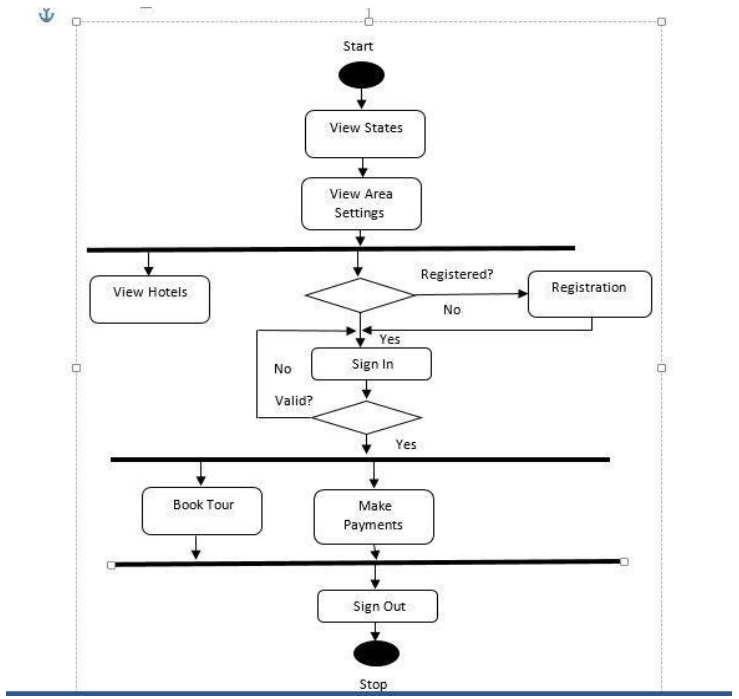

Fig 2:-Activity Diagram of a Tourist 


\section{Low Level Design:}

The entire software is broken down into modules to help the programmer to start coding. UML Class Diagram was used to model this phase. At this level, the relational database is shown with the primary keys and candidate keys. The relation of one class to another is carefully presented in the diagram below.

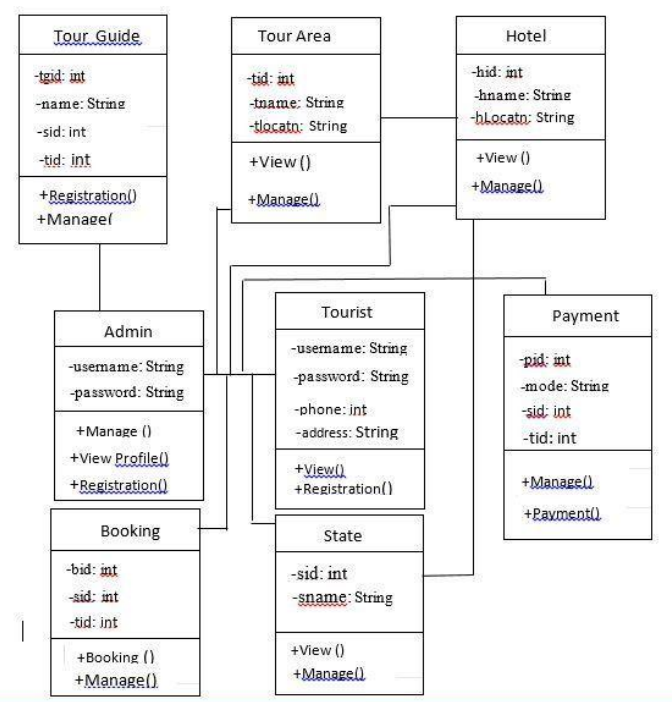

Fig 3:-Class Diagram of a Tourism Management System

\section{Results and Conclusion: -}

Today's advanced technology is culminating in the widespread use of computers and could serve as a basic for the automation of routine processes with a view to enhancing their delivery capabilities. The developments of information technology has a high influence on tourism development. Poor information results to inadequate analysis which leads to misguided policies on Tourism Management.

The information system has a task to collect, analyse and process existing information. It is an active object which deals with information and information processing. With an information system that provides a picture of how a tourist can make preparation for tour in a particular tour site(s), people from afar and near get access to information needed to embark on their tour with much ease and at their own comfort. The user friendliness of a system implies easy usage with little or no help from experts. Proper and effective automation would virtually eliminate the boredom associated with tourism work of registration and payment flow processes thereby effectively reducing work induced by stress to management staffs when using the manual system. The system when fully implemented will replace the manual system of registration and enhance the process of data collection, data query, data manipulation and data storage.

\section{References:-}

1. Agianaku, I. (2012). "Design and implementation of an airline flight information System", Caratis University, amorji-nike, Enugu. pp. 1-10.

2. Basu, P. K. (2003). Is Sustainable Tourism Development Possible? Broad issues concerning Australia and Pappau Guinea. In R.N. Gosh, M.A.B. Saddique \& Gabbay (Eds), Tourism and Economic Development: Case Study from Indian Region. Hamsphire, England.

3. Cooper, C., Fletcher, J., Gilbert, D. \& Wanhill, S. (1993). "Tourism: Principles and practice", Longman: Harlow, UK.

4. Inkeep, E. (1991). "Tourism Planning: An integrated and Sustainable Development Approach", Van Nostrand Reinhold: Newyork, USA.

5. Newsome, D., More, S.A. \& Dowling, R.K. (2002). Natural Area Tourism:

6. Yusuff, Mulkat A. and Akinde, Mukail A (2015) "Tourism Development and Economic Growth Nexus: Nigeria's Experience" European Journal of Hospitality and Tourism Research Vol.3, No.4, pp.1-10, Published by European Centre for Research Training and Development UK (www.eajournals.org). 